\title{
EL PAISAJE AGRÍCOLA COMO PATRIMONIO CULTURAL: BASES LEGALES PARA UN ANÁLSIS CRÍTICO
}

\author{
Eulalia Moreno Trujillo \\ Prof $^{\mathrm{a}}$ Titular Derecho civil \\ Universidad de Granada \\ Email: eulalia@ugr.es
}

"La cultura verdadera nace con la naturaleza, es simple, humilde y pura" MASANOBU FUKUOKA (filósofo y agricultor)

\section{Para Ramón, compañero y sobre todo amigo.}

RESUMEN: Desde finales del S.XX se introduce del paisaje como elemento del patrimonio cultural, como expresión de la interacción hombre-naturaleza, y una de las manifestaciones más antiguas y trascendentes de esa interacción es la agricultura. Se analiza el concepto de paisaje agrícola como paisaje cultural y su regulación legal, desde un punto de vista crítico, destacando sus carencias y dificultades, tanto como elemento natural, etnográfico y mixto y marcando las líneas de injerencia con el régimen jurídico general de la propiedad privada.

\section{PALABRAS CLAVE:}

ABSTRACT: Coming the 20th century to an end the landscape is recognized as cultural heritage, because of its development as a human - nature interplay, being the agriculture the earliest and most significant statement of this interplay. This article shows an analysis of the concept of agricultural landscape and its legal regulation from 
a critical point of view, highlighting its weaknesses and difficulties both as a natural, ethnographic or mixed element while pointing out the lines of interference with the legal system and the private propriety.

\section{KEYWORDS:}

\section{Proemio $^{1}$}

Con fecha 27 enero 2017 la UNESCO ha incluido la candidatura de los PAISAJES DEL OLIVAR DE ANDALUCÍA entre la lista indicativa española para ser declarados bienes integrantes del Patrimonio Cultural Mundial, previa la inclusión que por decisión del Consejo del Patrimonio Histórico se hizo de los mismos en la lista indicativa del Patrimonio Mundial de España ${ }^{2}$. Esta inclusión no es una mera declaración de principios sino que "pone de manifiesto nuestra riqueza patrimonial, al tiempo que constituye una muestra del compromiso de las administraciones y los ciudadanos por su conservación. Debemos tener en cuenta que la declaración de Patrimonio Mundial no es un fin en sí mismo, sino el principio de un camino de responsabilidades y compromisos cuya finalidad es el mantenimiento del valor universal excepcional de estas manifestaciones para las generaciones futuras",3, dado que los Estados proponentes deberán demostrar un nivel de protección adecuado del bien propuesto, adjuntado, en la

\footnotetext{
${ }^{1}$ A la hora de abordar este estudio, lo haré desde la perspectiva de la protección del patrimonio y su posible y necesaria- trascendencia sobre el régimen jurídico de la propiedad privada, sin entrar en analizar el sector agrícola y económico que representa el olivar en Andalucía.

${ }^{2}$ Recuperado de http://whc.unesco.org/en/tentativelists/6169/, última consulta 28/02/2018. En la última revisión llevada a cabo por la UNESCO de esta lista indicativa, el 5 de febrero de 2018, se encontraban incluidas 29 propuestas españolas. La inclusión en esta lista indicativa supone que el paisaje olivarero andaluz "Ilustra la evolución de la sociedad humana y sus asentamientos a lo largo del tiempo, condicionados por las limitaciones y/o oportunidades físicas que presenta su entorno natural y por las sucesivas fuerzas sociales, económicas y culturales, tanto externas como internas" (ítem 47 de las Directrices Prácticas para la aplicación de la Convención del Patrimonio Mundial, Organización de las Naciones Unidas para la Educación, la Ciencia y la Cultura, Comité Intergubernamental de Protección del Patrimonio Mundial, Cultural y Natural, texto en español coordinado y editado por Nuria Sanz, recuperado de http://whc.unesco.org/archive/opguide08-es.pdf , ultima revisión 28/02/2018) y obliga a los Estados solicitantes -en este caso España- a asumir el compromiso -siempre dentro de sus posibilidades- de preservar el patrimonio en cuestión, a través de las medidas legales, científicas, técnicas, administrativas y financieras adecuadas (ítem 53)

${ }^{3}$ En la presentación que se hace en la web del Ministerio de Educación, Cultura y Deporte al listado del Patrimonio Mundial,recuperado

de http://www.mecd.gob.es/cultura/areas/patrimonio/mc/patrimoniomundial/presentacion.html (última consulta 28/02/2018) se advierte que la misma es "una distinción que otorga la UNESCO a aquellos bienes con características de excepcional valor que los hacen únicos en el mundo... Los bienes declarados Patrimonio Mundial nos permiten hacer un recorrido por la historia de nuestro territorio...el pensamiento y la forma de actuar de cada momento se reflejan en los restos arqueológicos, en los monumentos, en nuestros cascos históricos o en el paisaje que fruto de la labor del ser humano se ha ido modelando a lo largo del tiempo..."
} 
propuesta de inscripción, los textos que contengan una clara explicación sobre cómo se implementa la protección jurídica del bien en cuestión bien de carácter legislativo, reglamentario o contractual ${ }^{4}$; camino cuya cabecera marca el art. 46 de nuestra Constitución de 1978: Los poderes públicos garantizarán la conservación y promoverán el enriquecimiento del patrimonio histórico, cultural y artístico de los pueblos de España y de los bienes que lo integran, cualquiera que sea su régimen jurídico y su titularidad. La ley penal sancionará los atentados contra este patrimonio.

El Olivar andaluz, candidato a ser declarado Patrimonio Cultural de la Humanidad, se calcula que está compuesto por más de 70 millones de olivos, habiéndose llegado a decir de él que constituye el "mayor bosque humanizado del mundo, o se le califica, más poéticamente, como "un mar de olivos".

Pero no son sólo los olivos lo que hace de este paisaje un objeto de protección legal, ya que -como advierte el Preámbulo del Convenio Europeo del Paisaje ${ }^{5}$-"el paisaje desempeña un papel importante de interés general en los campos cultural, ecológico, medioambiental y social, y que constituye un recurso favorable para la actividad económica y que su protección, gestión y ordenación pueden contribuir a la creación de empleo...” constituyendo, además “...un elemento importante de la calidad de vida de las poblaciones...". Es por eso por lo que a la hora de abordar el análisis del paisaje olivarero andaluz como objeto de protección jurídica deberemos tener en cuenta también todo el entramado de factores socioeconómicos, geográficos, históricos, industriales, que han hecho del Olivar, en Andalucía, un elemento definitorio de nuestra cultura: paisaje y patrimonio etnológico unidos en un único concepto jurídico.

\section{I.- APROXIMACIÓN AL CONCEPTO DE PAISAJE COMO OBJETO DE PROTECCIÓN JURÍDICA INTEGRADO EN EL PATRIMONIO CULTURAL}

Define el Diccionario de la Real Academia de la Lengua Española el paisaje como "parte de un territorio que puede ser observado desde un determinado lugar" o

\footnotetext{
${ }^{4}$ Items 96 y 97 de las Directrices prácticas para la aplicación de la Convención del Patrimonio Mundial, cit.supra: Las medidas legislativas y reglamentarias de ámbito nacional y local garantizarán la supervivencia del bien y su protección frente el desarrollo y los cambios que podrían afectar negativamente al Valor Universal Excepcional, o la integridad y/o la autenticidad del bien. Los Estados Partes también garantizarán la aplicación plena y eficaz de estas medidas.

${ }^{5}$ Florencia, 20/10/2000, ratificado por España el 26/11/2007
} 
bien "espacio natural admirable por su aspecto artístico", y añade el adjetivo "protegido" a sus definiciones calificándolo como "espacio natural que por sus valores estéticos y culturales, es objeto de protección legal para garantizar su conservación". Ya el propio Diccionario de la RALE se hace eco de esa necesidad de especial protección con finalidad garantista.

Frente a esta definición más común y menos formal, el art. 1 del Convenio Europeo del Paisaje define el paisaje como objeto de protección jurídica como "cualquier parte del territorio tal y como la percibe la población, cuyo carácter sea el resultado de la acción y la interacción de factores naturales y/o humano" (apartado a) y abarcará (ex art.2) áreas naturales, rurales, urbanas y periurbanas, zonas terrestres, marítimas y aguas interiores, integrando tanto a los paisajes excepcionales como a los cotidianos o degradados, buscando un ámbito de aplicación lo más amplio posible, con el objetivo de "promover la protección, gestión y ordenación de los paisajes" (art. 3). A tal fin se deberán formular por las autoridades públicas competentes "los principios generales, estrategias y directrices que permitan la adopción de medidas específicas con vistas a la protección, gestión y ordenación del paisaje" (art. 1.b), buscando alcanzar, para cada paisaje específicamente considerado, un "objetivo de calidad paisajística", entendiendo por tal "las acciones encaminadas a conservar y mantener los aspectos significativos o característicos de un paisaje, justificados por su valor patrimonial derivado de su configuración natural y/o la acción del hombre (art. 1.c).

Y dentro de estos paisajes de tan variada casuística, son especialmente definitorios de la cultura, de la tradición y de la experiencia los paisajes agrarios, entendidos - como hacen Egea-Fernández y Egea-Sánchez $(2012)^{6}$ - como "el resultado de un proceso de transformación del bosque primigenio para obtener la mayor diversidad de productos para la alimentación...como sistemas que surgen a lo largo de un proceso de coevolución de los seres humanos con el medio natural”.

Ser humano y naturaleza, que en su interrelación producen resultados como terrazas, dehesas, huertos, campiñas...en función de la combinación de elementos diversos: tipos y amplitud de las parcelas, sistemas de aprovechamiento, sistemas de

\footnotetext{
${ }^{6}$ En "Hacia una política de conservación y gestión de paisajes urbanos" comunicación publicada en las Actas del X Congreso de la Sociedad Española de Agricultura Ecológica SEAE, "20ªños impulsando la producción ecológica". Albacete, 26-29 septiembre 2012. Recuperado en http://www.agroecologia.net/recursos/publicaciones/actas/cd-actas-Xcongresoseae/actas/comunicaciones/85politica-egea.pdf última consulta 28/02/2018
} 
riego, régimen de explotación o el destino de la producción, los asentamientos humanos, los ingenios de explotación, etc. Elementos que van dando forma de manera lenta y continuada, sin prisa pero sin pausa, al paisaje: el hombre modaliza el medio natural y el medio natural modaliza al hombre en una relación recíproca inevitable.

Esta interacción permanente es causa última de la extrema complejidad que supone el tratamiento jurídico del paisaje agrícola o rural. Ya lo advierte Martínez Pisón $(1977)^{7}$ : "los paisajes son testimonio de un país pero envueltos en la vida"; "son el espejo de las relaciones, pasadas y presentes, del hombre con la naturaleza que le rodea, -como ilustran Lizet y De Ravignan (1987)- un negativo fotográfico sobre el que se deja una huella más o menos precisa y profunda, con todos los fenómenos posibles de sobreimpresión. Es por ello que el paisaje tiene una historia que contar o, por lo menos que nos invita a reconstruirla, a deducirla, desde esos fenómenos sobrevenidos... De tal forma que el análisis de los paisajes contribuye a revelar la historia de un país"8. Es el lienzo sobre el que el ser humano va dibujando su forma de vida: sus necesidades de alimento, de vestido, de abrigo, de comercio e intercambio, de desplazamiento, de sus gustos estéticos, de sus momentos lúdicos, de su creación artística

Proteger el paisaje agrario, por tanto, significa proteger la esencia de la cultura y de la historia de todo pueblo, siendo como es la agricultura una actividad que cuenta con más de 9.000 años de antigüedad. Resulta por tanto evidente la necesidad de establecer un marco jurídico apropiado, al servicio de la protección y conservación del paisaje agrario, pero también resulta evidente la enorme complejidad que exige el mismo, al integrar tantos y tan diversos elementos desarrollados y evolucionados a lo largo de tantos años.

\section{II.- EL DIFUSO MARCO JURÍDICO}

Cuando se aborda el estudio del paisaje como objeto de protección se le añade el adjetivo de "cultural", facilitando así la identificación de aquellos paisajes que por su singularidad trascienden la mera parcela de territorio que se contempla desde algún lugar. Son el "resultado de la interacción en el tiempo de las personas y el medio

\footnotetext{
${ }^{7}$ En "La evolución antrópica y la transformación voluntaria de los paisajes naturales" en "Medio Físico, Desarrollo regional y geografía", V Coloquio de Geografía, Facultad de Filosofía y Letras de la Universidad de Granada, Sección de Geografía, Granada, 3 al 6 de octubre de 1977, Ed. Asociación de Geógrafos Españoles - Universidad de Granada, 1977, págs. 157-161

${ }^{8}$ Lizet, B y de Ravignan, F., “Comprendre un paysage. Guide practique de recherch”, París, 1987, pág..14
} 
natural, cuya expresión es un territorio percibido y valorado por sus cualidades culturales, producto de un proceso y soporte de la identidad de una comunidad"'.

Este reconocimiento del carácter autónomo del paisaje como objeto de protección jurídica, y por lo tanto generador de derechos y obligaciones para los titulares públicos o privados, significa "establecer las bases para implicar a los distintos niveles de la Administración, a los sectores de actividad y a los grupos sociales en la valoración, mantenimiento y mejora de los paisajes culturales.

Son diversos los instrumentos legales que pretenden establecer el régimen jurídico del paisaje cultural ${ }^{10}$ :

- Convenios internacionales, como la Convención para la Protección del Patrimonio Mundial Natural y Cultural de la UNESCO (1972), ratificada por España diez años después, y cuyos criterios fueron revisados en 1992 para dar cabida a unos bienes específicos, de difícil encuadre en las categorías tradicionales, entre los que se encuentran los paisajes culturales ${ }^{11}$; término que se consagra los trabajos de un grupo de expertos en paisajes culturales ${ }^{12}$ (La Petite Pierre, Francia, 24-26 octubre 1992) (véase el documento WHC92/CONF.202/10/Add) y fue posteriormente aprobado para su inclusión en las Directrices Prácticas en la 16 a sesión del Comité del Patrimonio Mundial. En esta revisión, se califica el paisaje cultural como bienes culturales, como obras conjuntas del hombre y de la naturaleza, que ilustran la evolución de la sociedad y de los asentamientos humanos, bajo la influencia del entorno y de las fuerzas sociales, económicas y culturales sucesivas, internas y externas.

\footnotetext{
${ }^{9}$ Plan Nacional de Paisaje Cultural, aprobado en la sesión del Consejo de Patrimonio Histórico celebrada el 4 de octubre de 2012. Ministerio de Educación, Cultura y Deporte, Instituto del Patrimonio Cultural de España, Ed. 2015.

10 Para una enumeración más completa, véase http://www.mecd.gob.es/planesnacionales/dam/jcr:a2faf328-e614-434a-9eb9-43a89cf76a89/normativa-en-materia-de-paisaje.pdf; última revisión 28/02/2018

${ }^{11} \mathrm{Si}$ bien lo hacía de manera tangencial, sin otorgar un pleno reconocimiento al paisaje, al referirse a los "lugares" culturales: obras del hombre u obras conjuntas del hombre y la naturaleza así como las zonas, incluidos los lugares arqueológicos que tengan un Valor Universal Excepcional desde el punto de vista histórico, estético, etnológico o antropológico (art. 1). Después de la revisión de 1992, al integrar el concepto de "paisaje cultural" como entidad autónoma dentro del ámbito objetivo de protección de la Convención, como tipo específico de bien cultural y natural, junto a las "Ciudades históricas y centros de ciudad", los "Canales patrimoniales" y las "Rutas patrimoniales"

12 La Petite Pierre, Francia, 24-26 octubre 1992 (documento WHC-92/CONF.202/10/Add), posteriormente aprobado para su inclusión en las Directrices Prácticas (anteriormente citadas) en la 16a sesión del Comité del Patrimonio Mundial celebrada en Santa Fe, 1992 (WHC-92/CONF.202/10/Add y WHC92/CONF.002/12), citados en las propias Directrices
} 
Y son el reflejo de la implementación de técnicas concretas de utilización viable de las tierras, y pueden contribuir a las técnicas modernas conservando al mismo tiempo, o realzando, los valores naturales del paisaje, y a la biodiversidad.

- Normativa europea, destacando el Convenio Europeo del Paisaje, hecho en Florencia el 20/10/2000 y ratificado por España el 26/11/2007 (en vigor el 01/03/2008), advirtiendo precisamente la innovación que suponía fusionar en una visión integral del paisaje los conceptos de Patrimonio Cultural y Patrimonio Natural, y que venía precedido por la Carta del Paisaje Mediterráneo de 1993, la Recomendación $\mathrm{N}^{\mathrm{o}} \mathrm{R}(95) 9$ relativa a la Conservación de los Sitios Culturales integrada en las Políticas de Paisaje del Consejo de Europa, 1995 o la Carta Paneuropea de la CEMAT sobre el Patrimonio Rural, Resolución N ${ }^{\mathrm{o}} 2$ adoptada en la $15^{\mathrm{a}}$ sesión de la Conferencia de Ministros responsables de la ordenación del territorio del Consejo de Europa (CEMAT), Moscú, Federación julio de 2010, en la que se incorpora un apartado específico referido al patrimonio como centro de las dinámicas de paisaje y del territorio ${ }^{13}$; también debe mencionarse la Estrategia Territorial Europea (ETE) o European Spatial Development Perspective de la Unión Europea, Postdam 1999, en la que se reclama una política sólida para el paisaje que permita actuar preventivamente, tanto en los casos de presiones (urbana, de infraestructuras o agraria) como de abandono, estableciendo objetivos concretos para su conservación y su gestión ${ }^{14}$;

- y una amplia lista de normativa estatal y autonómica, encabezada por el art. 46 CE, y seguida por la Ley 16/1985 de 26 de junio del Patrimonio Histórico Español, al referirse a los "sitios históricos" como "el lugar o paraje natural vinculado a acontecimientos o recuerdos del pasado, a tradiciones populares, creaciones culturales o de la naturaleza y a obras del hombre, que posean valor histórico, etnológico, paleontológico o antropológico" (art. 15.4) se

\footnotetext{
${ }^{13}$ El Convenio Europeo del Paisaje establece que la conservación, gestión y mantenimiento del paisaje constituye un deber para todas las administraciones, estatales, regionales y locales, y tiene implicaciones en diversos ámbitos competenciales que influyen en el paisaje (Medio Ambiente, Agricultura, Cultura, Ordenación del Territorio, Vivienda, Urbanismo, Turismo...)y además requiere la implicación de la ciudadanía a través de organizaciones, fundaciones, asociaciones. Empresas e instituciones, Centros docentes y de investigación y profesionales expertos en las materias que inciden en el paisaje.

$14 \mathrm{http} / /$ ec.europa.eu/regional_policy/es/information/publications/reports/1999/european-spatial-developmentperspective, última revisión 28/02/2018.
} 
aproxima al concepto de paisaje, si bien no lo contempla específicamente; la

Ley del Suelo, Texto Refundido 2015, que en su art. 3 establece que "las políticas públicas relativas a la regulación, ordenación, ocupación, transformación y uso del suelo tienen como fin común la utilización de este recurso conforme al interés general y según el principio de desarrollo sostenible, sin perjuicio de los fines específicos que les atribuyan las Leyes...y... deben propiciar el uso racional de los recursos naturales armonizando los requerimientos de la economía, el empleo, la cohesión social, la igualdad de trato y de oportunidades, la salud y la seguridad de las personas y la protección del medio ambiente, contribuyendo en particular a...la eficacia de las medidas de conservación y mejora de la naturaleza, la flora y la fauna y de la protección del patrimonio cultural y del paisaje", añadiendo en el art. 5 que "todos los ciudadanos tienen derecho a... disfrutar de una vivienda digna, adecuada y accesible, ... y en un medio ambiente y un paisaje adecuados" configurando como deber (art. 6) "respetar y contribuir a preservar el medio ambiente y el paisaje natural absteniéndose de realizar actuaciones que contaminen el aire, el agua, el suelo y el subsuelo o no permitidas por la legislación en la materia"; y establece normas específicas de protección como la contenida en el art. 20, al delimitar la tipología de las edificaciones ${ }^{15}$. A ésta, se le suma la Ley 42/2007, de 13 de diciembre, del Patrimonio Natural y de la Biodiversidad, que sí recoge específicamente el concepto de paisajes protegidos en su art.35 como "partes del territorio que las Administraciones competentes, a través del planeamiento aplicable, por sus valores naturales, estéticos y culturales, y de acuerdo con el Convenio del Paisaje del Consejo de Europa, consideren merecedores de una protección especial"16; y obliga a la administración competente a cumplir, como objetivos de la protección, la conservación de

\footnotetext{
15 2. "Las instalaciones, construcciones y edificaciones habrán de adaptarse, en lo básico, al ambiente en que estuvieran situadas, y a tal efecto, en los lugares de paisaje abierto y natural, sea rural o marítimo, o en las perspectivas que ofrezcan los conjuntos urbanos de características histórico-artísticas, típicos o tradicionales, y en las inmediaciones de las carreteras y caminos de trayecto pintoresco, no se permitirá que la situación, masa, altura de los edificios, muros y cierres, o la instalación de otros elementos, limite el campo visual para contemplar las bellezas naturales, rompa la armonía del paisaje o desfigure la perspectiva propia del mismo".

${ }^{16}$ Definiéndolo, precisamente, en función de la necesidad de protección para la conservación de sus valores característicos, siguiendo la línea previamente establecida por el art.1,d) del Convenio Europeo del Paisaje
} 
los valores singulares de cada paisaje, la preservación de la interacción entre naturaleza y cultura y -enlazando con el concepto de patrimonio etnológico o patrimonio cultural inmaterial- el mantenimiento de las prácticas de carácter tradicional (art. 35.2 y 3). Este texto legal integra los paisajes protegidos dentro de la categoría general de "espacios naturales protegidos" y, como tales, deja la gestión en manos de la comunidad autónoma en que se integre territorialmente, y reconociendo la posibilidad de expropiación por causa de protección (al implicar la declaración como paisaje protegido la declaración de utilidad pública) y facultar a la Comunidad autónoma competente al ejercicio de los derechos de tanteo y retracto "respecto de los actos o negocios jurídicos de carácter oneroso y celebrados intervivos que comporten la creación, transmisión, modificación o extinción de derechos reales que recaigan sobre bienes inmuebles situados en su interior" (art. 40). Si el paisaje del que se trate está integrado en la Red Natura 2000 se prevén medidas específicas de fomento a la conservación y protección a través de prioridad en el acceso a subvenciones, bonificaciones en tasas, gastos de inscripción registral o cuotas patronales de la Seguridad Social agraria (art. 42). Para facilitar estas acciones, se creará un Inventario Nacional de Espacios Naturales Protegidos, Red Natura 2000 y Áreas protegidas por Instrumentos Internacionales ${ }^{17}$.

La legislación estatal establece también un Plan Nacional de los Paisajes ${ }^{18}$, dentro del cual específicamente se llevó a cabo (como proyecto de investigación) un estudio temático comparativo sobre los paisajes del Olivo en España ${ }^{19}$, elaborado en

\footnotetext{
${ }^{17}$ Cuyo régimen de protección -según el art. 50- será el establecido en los correspondientes convenios y acuerdos internacionales, si bien el Ministerio competente en colaboración con la Comunidad Autónoma implicada elaborará, en el marco del Plan Estratégico Estatal del Patrimonio Natural y la Biodiversidad, unas directrices de conservación que constituirán el marco orientativo para la planificación y gestión de dichos espacios.

${ }^{18}$ Cuya finalidad fundamental es promover la salvaguarda de los paisajes de interés cultural, estableciendo las medidas encaminadas a garantizar la viabilidad del paisaje cultural: identificación y caracterización, documentación, investigación, protección, mejora, y revitalización, cubriendo los aspectos necesarios de definición, delimitación, análisis de componentes y gestión; todo ello desde una perspectiva de desarrollo sostenible.

19 Recuperado en http://www.mecd.gob.es/planes-nacionales/dam/jcr:40ed82a2-bac0-4973-af3bdb7bc23a8c05/05-02-paisajes-del-olivo-en-espana.pdf , última revisión 28/02/2108. "El proyecto ha sido realizado gracias a las ayudas prestadas a empresas privadas para proyectos de puesta en valor, promoción, difusión y protección de bienes declarados patrimonio cultural, correspondientes al año 2012 (establecidas en la Resolución de 24 de mayo de 2012, de la Dirección General de Bellas Artes y Bienes Culturales en materia de protección del Patrimonio Histórico, Ministerio de Educación cultura y Deporte (B.O.E. N ${ }^{\circ} 145$ de 18 de junio de 2012), la mencionada Dirección General de Bellas Artes y Bienes
} 
2012, y entre cuyos objetivos se encuentra conseguir una valoración patrimonial (económica, cultural, social, medioambiental, espiritual, etc,) teniendo en cuenta tanto los valores intrínsecos de la unidad como aquellos extrínsecos, derivados de su inserción en un entorno más amplio. Destaca este estudio cómo hay que tener en cuenta también otros aspectos que influirán de forma decisiva en las futuras acciones de gestión: la fragilidad, la conectividad o la funcionalidad; añadiendo el dinamismo y la permanente evolución, cualidades intrínsecas que son de todo paisaje. Y todo ello puesto al servicio de una acertada gestión y eficaz salvaguarda.

- Es la legislación autonómica la que aparece como mayor "productora" de normas: son muchas las comunidades que, asumiendo las competencias en materia de gestión que tienen atribuidas han legislado con mayor o menor éxito en materia de protección del patrimonio cultural, natural o mixto ${ }^{20}$.

En Andalucía, siendo como es la Comunidad Autónoma con mayor número de hectáreas dedicadas al olivar, y que precisamente ese cultivo es el identificador relevante para la inclusión en la Lista indicativa de la Unesco, la protección al paisaje olivarero tiene dos referentes legales fundamentales: por un lado, la Ley del Olivar de 2011 (LEY 5/2011, de 6 de octubre); y por otro el Plan Director del Olivar, aprobado por Decreto 103/2015, de 10 de marzo.

La Ley del Olivar lo reconoce como el agrosistema más representativo y simbólico de Andalucía y es considerado como estratégico. "Enraizado en el territorio de nuestra comunidad desde su prehistoria,- afirma el preámbulo de la Ley- el olivo silvestre se domestica en época fenicia. A partir de entonces el paisaje de olivar ha dado forma tanto a las campiñas como a las sierras andaluzas"; "puede decirse -añade el legislador- que, si hay un cultivo arraigado en la cultura milenaria de Andalucía, ese es sin duda el olivar, que ha sido fuente de inspiración literaria, musical y pictórica de nuestros artistas, además de seña de identidad de muchos de los grandes movimientos sociales que se han desarrollado en nuestra región". Es por ello por lo que esta ley pretende ayudar a la preservación de los paisajes agrarios tradicionales y al

Culturales ha financiado el presente proyecto sobre El Paisaje de los Olivos", se afirma en su presentación.

${ }^{20}$ Puede consultarse, a estos efectos así como para la consulta en materia de normativa internacional y nacional el Plan Nacional de Paisajes Culturales, que contempla específicamente un apartado dedicado a la enumeración de la normativa aplicable http://www.mecd.gob.es/planes-nacionales/dam/jcr:a2faf328e614-434a-9eb9-43a89cf76a89/normativa-en-materia-de-paisaje.pdf 
mantenimiento de la diversidad biológica... y ... debe asegurar, promover y valorizar un patrimonio acumulado por Andalucía durante centenares de años, que es seña de identidad, de pertenencia y de liderazgo". Y entre otros objetivos ${ }^{21}$, la ley se plantea contribuir al mantenimiento de la singularidad de los paisajes y de los efectos ambientales positivos asociados al olivar, imponiéndose como finalidad a conseguir la de conservar y valorizar el paisaje y el patrimonio histórico y cultural del olivar y sus productos (apartado f) del art... Para articular la consecución de este objetivo, incluye, bajo la expresión "territorio de olivar" el espacio geográfico en el que el cultivo del olivar y la producción de aceite de oliva y aceituna de mesa es determinante por su importancia para la economía, el empleo o el mantenimiento de la población en el medio rural. Asimismo, también se entenderá como tal el espacio geográfico en el que el olivar sea predominante en la configuración de los paisajes y contribuya de manera relevante a la conservación de la biodiversidad y del patrimonio natural (art. 2). Como vemos, lamentablemente, se vuelve a la dicotomía patrimonio natural/patrimonio cultural a la hora de ofrecer un marco jurídico que regule el paisaje, sin conseguir el tratamiento unitario que debería exigirse. Esta distinción -que conceptualmente tiene difícil sostenimiento- se mantiene en el Título $\mathrm{V}$, que incluso en su encabezamiento ya predica la distinción de un lado del aspecto natural-ecológico-biológico y de otro el aspecto etnológico del cultivo del Olivar, al dedicarlo a "La tutela del Patrimonio Natural Olivarero y de la Cultura del Aceite y de la Aceituna”. Este título contiene un solo artículo (el 39), intitulado "El olivar y el patrimonio natural e histórico" (insiste en la diferenciación, como si fueran dos manifestaciones separadas de una sola realidad): “1. En los términos de lo previsto en la Ley 42/2007, de 13 de diciembre, del patrimonio natural y de la biodiversidad, y en la Ley 14/2007, de 26 de noviembre, de patrimonio histórico de Andalucía, los órganos competentes de la Administración de la Junta de Andalucía tendrán en cuenta la importancia y singularidad de los territorios de olivar, de los olivos y sus productos, como parte del patrimonio natural y cultural de Andalucía, para emprender acciones tendentes a: a) Establecer medidas de protección y conservación del patrimonio representado por los olivos y olivares singulares o

\footnotetext{
${ }^{21}$ Junto con el resto de objetivos planteados: - avanzar en la eficiencia de nuestros territorios y del sector del olivar de forma equitativa y sostenible, - ser un instrumento esencial para el asentamiento de las personas, la generación de empleo, un mayor progreso del medio rural y de sus habitantes y una superior calidad de vida, y la cohesión social y territorial, -orientar nuestros productos hacia el mercado y propiciar estabilidad al sector, - impulsar la mejora del modelo productivo, en base a la industria agroalimentaria y la transparencia en la cadena de valor, - aumentar nuestra capacidad de respuesta ante los cambios de los mercados y los cambios tecnológicos, y ante las amenazas climáticas.
} 
excepcionales, cuando se acrediten valores de edad, monumentalidad, producción excepcional y relevancia cultural o histórica. b) Impulsar medidas de apoyo a la protección, conservación y uso del patrimonio arqueológico, industrial y etnológico asociado al cultivo del olivar y el aceite de oliva. c) Impulsar actividades para informar y educar a los habitantes de los territorios olivareros sobre la potencialidad e interés público que tiene el buen uso de este patrimonio natural y cultural. d) Impulsar planes de actividades culturales en los territorios olivareros, favoreciendo la participación y la iniciativa de entidades públicas y privadas. e) Divulgar, para el conocimiento de los consumidores, las características de calidad intrínseca del aceite de oliva y de la aceituna de mesa, y los efectos saludables de su consumo. f) Impulsar la identificación de paisajes olivareros de especial relevancia histórica, cultural, agronómica o ambiental y establecer medidas de puesta en valor, así como realizar un programa de señalización y localización. 2. Asimismo, y de conformidad con la normativa específica aplicable, se resaltarán los valores del turismo y la artesanía asociados con el olivar, el aceite de oliva y la aceituna de mesa, y con los procesos de diversificación y, en su caso, reconversión a otros usos". Y todo ello bajo el principio del interés histórico-cultural y social del cultivo del olivar y de sus productos derivados en Andalucía, que proclama el art.4”.

Para la consecución de los fines propuestos en la Ley, se prevé la elaboración de un Plan Director del Olivar (art. 5) que comprenderá la delimitación geográfica de los territorios del olivar, la tipología del olivar así como la caracterización de las explotaciones, y sobre todo, el diagnóstico desde las perspectivas económica, social, ambiental y cultural, implementando las estrategias de actuación. Este Plan se aprobó, con el respaldo del Consejo Andaluz del Olivar, por Decreto 103/2015, de 10 de marzo, que dedica el apartado 2.10.2.6. al análisis del Olivar andaluz como Patrimonio cultural: las tradiciones, las fiestas, la artesanía o la gastronomía , manifestaciones de interés artístico, ambiental, histórico, arqueológico, documental, científico y técnico y que "constituye un elemento fundamental y básico no sólo como referencia histórica, sino por haber intervenido directamente en la conformación de la realidad actual"22; promoción y desarrollo de rutas turísticas, evaluación y catalogación de la arquitectura rural, la relación con la dieta mediterránea, la conservación de actividades tradicionales y artesanales relacionadas con la agricultura. Sin embargo, a la hora del diagnóstico, se concluye que el ${ }_{22}^{22}$ http://www.juntadeandalucia.es/export/drupaljda/Plan\%20Director\%20del\%20Olivar.pdf, recuperado 
patrimonio cultural, paisajístico y natural del olivar está infrautilizado, desaprovechando su potencialidad para la diversificación de actividades económicas ${ }^{23}$. Es por ello por lo que, entre las estrategias y actuaciones se prevé la protección del olivar tradicional, especialmente del ubicado en zonas con desventajas naturales específicas, la conservación y puesta en valor del patrimonio natural, arqueológico, genético, etnológico, gastronómico e industrial del olivar andaluz, impulsando desde los poderes públicos, medidas de protección y apoyo del patrimonio representado por los olivos y olivares singulares o excepcionales, y del patrimonio arqueológico, industrial y etnológico asociado al cultivo e impulsar la localización, señalización y puesta en valor de paisajes olivareros de especial relevancia histórica, cultural, turística o agronómica, tomando como referencia proyectos como el "Registro de Paisajes" del Instituto Andaluz del Patrimonio Histórico, o el "Atlas del Patrimonio Inmaterial de Andalucía”.

\section{II.- LOS ELEMENTOS INMATERIALES DEL PAISAJE AGRÍCOLA PROTEGIDO: EL PATRIMONIO ETNOLÓGICO}

La legislación española, en concreto la Ley 42/2007, de 13 de diciembre, del Patrimonio Natural y de la Biodiversidad, prevé en el marco de sus competencias objetivas (centradas fundamentalmente en la protección y conservación de espacios de gran valor ecológico y, entre otros, los paisajes naturales) prevé la promoción de los conocimientos tradicionales para la conservación del Patrimonio Natural y la Biodiversidad, estableciendo una serie de deberes impuestos a las Administraciones competentes (art.74): Deberán establecer las medidas necesarias para preservar, mantener y fomentar los conocimientos y las prácticas de utilización consuetudinaria que sean de interés para la conservación y el uso sostenible del patrimonio natural y de la biodiversidad; deberán promover el reparto equitativo de los beneficios que se deriven de la utilización de estos conocimientos y prácticas; y para facilitar su cumplimiento, se elaborarán Inventarios de los Conocimientos Tradicionales relevantes para la conservación y el uso sostenible de la biodiversidad y geodiversidad, con especial atención a los etnobotánicos. Éstos se integrarán en el Inventario Español de los Conocimientos Tradicionales relativos al Patrimonio Natural y la Biodiversidad (sometidos a las normas de protección de la propiedad intelectual e industrial y en

\footnotetext{
${ }^{23}$ Págs. 112 y ss, Plan Director del Olivar, cit.
} 
concreto de patentes). Estos territorios serán objeto de planes especiales de custodia (art. 76), a través de acuerdos vinculantes entre las administraciones competentes y los propietarios de las fincas (sean de titularidad pública o privada); y para el cumplimiento de estos fines de conservación y protección se prevé la instauración de un Fondo del que podrán participar los particulares propietarios de fincas afectadas (art. 78), como medida de ayuda a la ejecución de actuaciones como son: la inversión, gestión y ordenación forestal; hacer viables los modelos de gestión sostenible en materia de silvicultura, actividades cinegéticas y piscícolas; poner en valor y promover las funciones ecológicas, sociales y culturales de los espacios forestales y las llevadas a cabo por los agentes sociales y económicos ligados a los espacios naturales protegidos; apoyar las acciones de prevención de incendios forestales; incentivar la agrupación de la propiedad forestal para el desarrollo de explotaciones forestales conjuntas, que favorezcan la gestión forestal sostenible; promocionar la obtención de la certificación forestal o promover el uso y el apoyo a la producción y comercialización de productos procedentes de espacios naturales protegidos, Red Natura 2000 y bosques certificados. Incluirán también la preservación, mantenimiento y fomento de los conocimientos y las prácticas de utilización consuetudinaria que sean de interés para la conservación y el uso sostenible del patrimonio natural.

$\mathrm{Si}$, como acabamos de ver, resultan de gran valor los elementos naturales en la definición de un paisaje protegido, siendo así que originariamente eran precisamente los paisajes que por su alto valor medioambiental los que gozaban de protección, son esenciales los elementos inmateriales, en el sentido establecidos por los artículos $46 \mathrm{y}$ 47 de la Ley 16/1985 de , Histórico Español, al entender incluidos entre los bienes integrantes del Patrimonio Histórico "los bienes muebles e inmuebles y los conocimientos y actividades que son o han sido expresión relevante de la cultura tradicional del pueblo español en sus aspectos materiales, sociales o espirituales" (art. $46)^{24}$. Protección a la que España viene obligada al haber ratificado en 2006 la

\footnotetext{
${ }^{24}$ Artículo 47: 1. Son bienes inmuebles de carácter etnográfico, y se regirán por lo dispuesto en los títulos II y IV de la presente Ley, aquellas edificaciones e instalaciones cuyo modelo constitutivo sea expresión de conocimientos adquiridos, arraigados y transmitidos consuetudinariamente y cuya factura se acomode, en su conjunto o parcialmente, a una clase, tipo o forma arquitectónicos utilizados tradicionalmente por las comunidades o grupos humanos.

2. Son bienes muebles de carácter etnográfico, y se regirán por lo dispuesto en los títulos III y IV de la presente Ley, todos aquellos objetos que constituyen la manifestación o el producto de actividades laborales, estéticas y lúdicas propias de cualquier grupo humano, arraigadas y transmitidas consuetudinariamente.

3. Se considera que tienen valor etnográfico y gozarán de protección administrativa aquellos conocimientos o actividades que procedan de modelos o técnicas tradicionales utilizados por una
} 
Convención para la Salvaguarda del Patrimonio Cultural Inmaterial, firmada en 2003, en la cual se configuran como objeto de protección los conocimientos y actividades relacionados con las formas de vida tradicionales.

Sin embargo, la protección que ofrece la propia LPH no resulta operativa: lo que hace el legislador es subsumir la protección del patrimonio etnológico en los criterios generales de protección que ya contempla para los bienes muebles e inmuebles, siendo así que resulta prácticamente imposible aplicar los títulos II, III y IV a las actividades y conocimientos. Esta remisión sí puede resultar efectiva para bienes muebles e inmuebles (al fin y a la postre se integran en la tradicional dicotomía que recoge el Código civil), pero difícilmente a las tradiciones y expresiones orales (incluido el idioma), las artes escénicas, las prácticas sociales, rituales y festejos, los conocimientos y prácticas relativos a la naturaleza y al universo o la artesanía tradicional como medio y no como resultado $^{25}$. Difícilmente podemos calificar como BIC, y someter a su régimen jurídico a la Semana Santa o a los cantes de trilla... En cuanto actividades y conocimientos tradicionales, la LPH se limita a ordenar a la Administración que otorgue "protección", y si se encuentran en manifiesto riesgo de desaparición "se adoptarán las medidas oportunas conducentes al estudio y documentación científicos de estos bienes"... No habla de conservación, preservación para generaciones futuras... Habla de estudio y documentación: existió y fue así, pero la hemos dejado extinguir.

Resulta especialmente "trágico" el gran número de actividades y tradiciones ligadas a la explotación agraria que se han perdido debido a la modernización y mecanización de la actividad agraria, que sólo perviven ya en la memoria de nuestros mayores, y que influían en el modo de vida de las comunidades rurales, definiendo sus costumbres, sus viviendas, sus vestidos o incluso sus relaciones sociales, y por ende, sus paisajes (las eras, particulares o comunales, para servir a la trilla del cereal o las leguminosas; las cuadras para las bestias de laboreo; los cultivos de forraje para los

determinada comunidad. Cuando se trate de conocimientos o actividades que se hallen en previsible peligro de desaparecer, la Administración competente adoptará las medidas oportunas conducentes al estudio y documentación científicos de estos bienes.

${ }^{25}$ Son numerosas las normas legales autonómicas que recogen una serie de medidas para salvaguardar este tipo de patrimonio, si bien se carece de una norma general que marque las líneas directrices. Ver, en este sentido ALEGRE ÁVILA, J.M, "El patrimonio etnológico: un patrimonio cultural sin régimen jurídico" en Revista $\mathrm{PH}$, $\mathrm{n}^{\mathrm{o}}$ 82, 2012, ed. electrónica, recuperada en http://www.iaph.es/revistaph/index.php/revistaph/article/view/3311\#.WpvldmrOXIU, última revisión 29/02/2018. 
animales; la gastronomía; las fiestas que marcaban el calendario agrícola y ganadero, como las ferias de ganado o el remate de la aceituna...).

Parece que a la Administración le faltan recursos para la conservación y mantenimiento vivo de estos elementos del patrimonio etnológico, limitándose a instar su salvaguarda en soportes materiales para garantizar su transmisión a las generaciones futuras, encerrando en museos los cadáveres momificados de esas costumbres, de esos conocimientos, de esas tradiciones, resignándose a su pérdida.

\section{III.- PAISAJE AGRÍCOLA PROTEGIDO Y DERECHO DE PROPIEDAD PRIVADA: NECESIDAD DE DELIMITACIÓN DE UN RÉGIMEN JURÍDICO ESPECÍFICO}

De este confuso panorama legislativo podemos destacar dos ideas fundamentales: en primer lugar, que proteger el paisaje implica-necesariamente- alterar el régimen general del derecho de propiedad, limitando o modalizando los poderes y facultades del propietario, primando el interés público a la conservación y protección del patrimonio paisajístico cultural sobre el interés del propietario agrícola particular y en segundo lugar que la regulación jurídica de los paisajes protegidos en España se hace, mayoritariamente, a través de normas transversales y se echa en falta una normativa específica y omnicomprensiva, que facilite la acción de la Administración competente y el respeto por la colectividad.

En cuanto a la primera idea, ya la calificación como propiedad agraria significa una modalización del contenido general de la propiedad: se habla así de un estatuto básico de la propiedad agraria, que recoge como definidores del mismo los derechos de cultivo, plantación y explotación, equilibrados con el deber de conservación y el derecho de mejora. Los derechos de aprovechamiento tienen unas características específicas, centrándose en el derecho de uso y aprovechamiento y el arrendamiento rústico. Para su consecución, se regula el derecho de instalación, construcción y edificación y se pone al servicio de la actividad agraria el derecho de uso hidrológico. La explotación agraria general un tipo especial de empresa, con unos caracteres determinados; y la administración interviene directamente a través de ordenación del 
territorio actuando sobre la parcelación, y estableciendo políticas agrarias y medioambientales ${ }^{26}$.

A esta delimitación del contenido del derecho de propiedad, hay que añadir la que nace de la incorporación de concepto de paisaje agrario protegido, calificando como Paisajes de Interés Cultural aquéllos definidos por una actividad agraria de valor supraeconómico, es decir "como aquellos ámbitos en los que los valores patrimoniales considerados significativos de cada Demarcación se muestren más reconocibles por su representatividad social y cultural, su integridad y estado de conservación, su autenticidad y singularidad, etcétera.": así, la declaración como Paisaje de Interés Cultural Olivarero de Sierra Mágina (Jaén), o el Paisaje Agrario del Valle de Lecrín (Granada) o el Paisaje agrario de Ohanes (Almería), dependientes de la Junta de Andalucía $^{27}$. Esta declaración -de naturaleza administrativa ${ }^{28}$ - supone "la asignación de valores patrimoniales a una parte del territorio, aunque no existan actualmente figuras jurídicas de protección en la administración cultural andaluza directamente referidas a los paisajes”, afirma Rodrigo Cámara (2012), llevándose a cabo una mínima actuación a través del planeamiento del suelo.

Cuando el Paisaje de Interés Cultural se solape con la calificación de Espacio natural protegido contemplado en la Ley 42/2007, de 13 de diciembre, del Patrimonio Natural y de la Biodiversidad (por aparecer así integrado en el Inventario previsto en el art. 51 de dicha Ley) genera un régimen legal específico que afecta al contenido del derecho de propiedad por lo que debe hacerse constar en el Registro de la Propiedad territorialmente competente ${ }^{29}$ recogiéndose información sobre las lindes de las fincas

\footnotetext{
${ }^{26}$ En una visión muy general y simplista de lo que supone la muy compleja realidad de la propiedad agraria en la actualidad

${ }_{27}$ En http://www.iaph.es/web/canales/patrimonio-cultural/paisaje-cultural-andalucia/paisajes-de-interescultural-andalucia/index.html última revisión 28/02/2018

${ }^{28}$ Ver RODRIGO CÁMARA et al, "Registro de paisajes de interés cultural de Andalucía. Criterios y metodología", en Revista PH (versión electrónica), del Instituto Andaluz del Patrimonio Histórico, cit.

29 Art. 53 "La información perimetral referida a espacios naturales protegidos, Red Natura 2000, los montes de utilidad pública y los dominios públicos de las vías pecuarias y zonas incluidas en el Inventario Español de Zonas Húmedas, integradas en el Inventario Español del Patrimonio Natural y de la Biodiversidad, quedará siempre incorporada al sistema de información geográfica de la finca registral, con arreglo a lo dispuesto en la legislación hipotecaria.

3. En toda información registral, así como en las notas de calificación o despacho referidas a fincas, que según los sistemas de georreferenciación de fincas registrales, intersecten o colinden con ámbitos espaciales sujetos a algún tipo de determinación medioambiental,... se pondrá de manifiesto tal circunstancia como información territorial asociada y con efectos meramente informativos, recomendando en cualquier caso, además, la consulta con las autoridades ambientales competentes.

4. Igualmente, el Catastro Inmobiliario tendrá acceso a la información a que se refiere el apartado segundo, en los términos previstos en esta ley, de conformidad con lo dispuesto en su normativa reguladora"
} 
afectadas (como parte de la descripción geográfica existente en la anotación registral) y haciendola constar "en toda información registral, así como en las notas de calificación o despacho referidas a fincas, que según los sistemas de georreferenciación de fincas registrales, intersecten o colinden con ámbitos espaciales sujetos a algún tipo de determinación medioambiental", poniendo de manifiesto "tal circunstancia como información territorial asociada y con efectos meramente informativos, recomendando en cualquier caso, además, la consulta con las autoridades ambientales competentes"; y ello porque la protección de esos valores ambientales puede afectar al uso y disfrute de la finca al primar el interés general a la defensa de la biodivesidad y los valores naturales sobre el interés particular del propietario de la finca.

Ya lo advertía Fernández Salinas (2008) ${ }^{30}$ : "La pertenencia a la Lista del Patrimonio Mundial se ha asumido en España frecuentemente como un reto para convertir poblaciones y territorios en destinos atractivos dentro del campo emergente del turismo cultural; en cambio, la filosofía de la Lista, que otorga más responsabilidades que privilegios, es relegada a un segundo plano. Los compromisos aceptados en el momento de la inclusión, entre ellos los planes de gestión, son a menudo olvidados o sometidos en todo caso a proyectos urbanos poco sensibles con el patrimonio y veleidosos respecto a una pretendida modernización urbana o a la simple especulación inmobiliaria... Respecto del paisaje, la realidad se encuentra mucho más desprotegida: desde las propias instituciones públicas - denuncia el autor- no sólo no se protege el paisaje, sino que ignoran su responsabilidad"

Respecto a la segunda idea, creo que basta para su justificación la somera recopilatio que en el apartado anterior se ha mostrado: Estamos en un ámbito de desarrollo legislativo muy joven; el concepto de paisaje protegido no alcanza plena entidad propia hasta finales del S.XX o principios del XXI; pero aún así, estamos luchando contra los conceptos tradicionales de patrimonio cultural, entendido habitualmente como bienes muebles o inmuebles, de valor histórico o artístico: cuadros, esculturas, monumentos o restos arqueológicos. Nos cuesta entender que el paisaje producto de la actividad agraria pueda asimilarse al conjunto monumental de la Alhambra y el Generalife o a las Meninas de Velázquez en cuanto a la trascendencia para la cultura,

\footnotetext{
${ }^{30}$ En "La protección del Patrimonio Mundial en España", Revista PH (versión electrónica), del Instituto Andaluz del Patrimonio Histórico, $\mathrm{n}^{\mathrm{o}} \quad 2, \quad 2008$, recuperado en http://www.revistadepatrimonio.es/revistas/numero2/gestion/estudios/articulo.php útlima revisión 28/02/2018
} 
para la sociedad actual y por su necesidad de protección: podemos perfectamente entender el control de visitantes a los Reales Alcázares de Sevilla, y ¿a los olivares de Torres (Jaén)? Lamentablemente creo que la sociedad, en general, aún no concibe la actividad agrícola ${ }^{31}$ como un arte, como un elemento esencial de la cultura que nos ha llevado a ser tal y como somos en la actualidad, y cuyo lienzo no se encuentra en un marco de madera y se muestra en un espacio cerrado, sino que se dibuja en la tierra, en los surcos de las labores de siembra, que mancha las manos del que la modela y muestra al mundo, sin limitaciones, su obra definitiva. Y es que, en palabras de Rodrigo Cámara (2012) ${ }^{32}$, “es importante reseñar que un paisaje de interés cultural no pretende ser, al menos en el momento actual, una figura administrativa de protección de bienes culturales. Sin embargo, toda vez que se defiende el paisaje como construcción social y cultural, éste deberá entenderse como un bien cultural con pleno valor como elemento integrante del patrimonio cultural de Andalucía ... A través del paisaje -continúa el autor- se abren nuevos caminos de gestión de los bienes culturales, participando de la orientación actual sobre el tratamiento del patrimonio cultural, que no se dirige como único destino a la creación de delimitaciones para la protección, sino también hacia aspectos relacionados con la educación o didáctica patrimonial, el desarrollo territorial, la participación pública, la gobernanza territorial o, incluso, como clave del bienestar social”. El paisaje vive, como "protegido" en un limbo jurídico sin llegar a una definición específica, sin que queden claros los mecanismos legales de protección, tanto preventivos (planes administrativos), delimitación del contenido de los derechos de titularidad y aprovechamiento (desde el punto de vista sustantivo) tanto en facultades como en deberes, como sancionatorios. Todo ello integrando un sistema legal transversal, que incluya los valores naturales (la íntima relación del paisaje agrícola con los ecosistemas y la defensa del medio natural) así como los valores etnológicos o inmateriales de los que hemos hablado anteriormente. Se hace pues, necesaria, como mínimo, "una reflexión institucional, normativa y técnica sobre lo que debe entenderse por paisaje de interés cultural y por relación con el paisaje de los bienes culturales (o dimensión paisajística de los bienes culturales), todo ello en fondo y forma; es decir, en cuanto al concepto y en cuanto a su tratamiento" (Rodrigo Cámara (2012)), dado que, esencialmente, este tratamiento jurídico se limita a acciones en materia de gestión del suelo, como ya hemos destacado, dejando huérfanos otros aspectos esenciales del paisaje cultural.

\footnotetext{
31 “Agricultura” (del latín agri 'campo', y cultūra 'cultivo', 'crianza'), el arte de cultivar la tierra.

${ }^{32}$ En "Registro de paisajes de interés cultural de Andalucía. Criterios y metodología”, cit. pág.4.
} 
Esta necesidad ha llegado incluso al Defensor del Pueblo Andaluz, que en la Actuación de Oficio formulada en el Expediente 16/2946 y dirigida a la Consejería de Medio Ambiente y Ordenación del Territorio, sobre el negocio de la venta de olivos y otros árboles de cierta longevidad, generalmente centenarios que "forman parte del patrimonio natural y, pese a ello, no cuentan con una normativa específica ad hoc que les dote de la debida protección que impida que se conviertan en fuente de mercadeo y negocio... cuando la inexistencia de normativa específicamente protectora, per se, de estos bienes naturales que forman parte de nuestro acervo cultural, de nuestro paisaje y de nuestro entorno, está permitiendo lo que algunos no dudan en calificar como verdadero expolio, por la pérdida que supone para la ciudadanía tanto en términos estrictamente materiales, como en cuanto a su carácter de patrimonio natural"33 A pesar de la existencia de algunos instrumentos normativos, como la Ley 8/2003, de 28 de octubre, de la Flora y Fauna Silvestres, o el Decreto 225/1999, de 9 de noviembre, de regulación y desarrollo de la figura del Monumento Natural de Andalucía, o la Ley 5/2011 de 6 octubre del Olivar, ya mencionada, la protección ofrecida es por sí misma insuficiente que exige que los poderes públicos se "adelanten" o prevean medidas para evitar esas "transferencias" de patrimonio natural andaluz hacia otros lugares, con la consiguiente e irreparable pérdida para nuestra Comunidad. Son normas que contienen meramente principios programáticos, denuncia el Defensor del Pueblo andaluz, sin eficacia protectora real. Por todo ello sugiere: "que, previos los trámites legales oportunos, se promueva la aprobación de una norma de protección del patrimonio natural andaluz constituido específicamente por árboles y arboledas singulares que no estén declarados monumentos naturales de Andalucía o no estén ubicados en espacios naturales protegidos, en función de la concurrencia objetiva y determinada en ellos de alguna o de varias circunstancias tales como edad, altura, tamaño o cualesquiera otras circunstancias que se consideren relevantes y que les dote de singularidad o los haga susceptibles de ser resguardados, a fin de evitar con ello que estos elementos del patrimonio natural andaluz puedan ser objeto de compraventa que implique su arranque, transporte y trasplante con finalidad decorativa fuera de la Comunidad Autónoma de Andalucía." La respuesta de la Consejería interpelada, el 2 de diciembre de 2016 rechazó, por innecesaria, tal sugerencia, al entender que los olivos ya se encuentra suficientemente protegidos, a través del Catálogo de Árboles y Arboledas Singulares y la Ley del Olivar y Planes conexos. Fuera de tal

$33 \mathrm{http}: / / \mathrm{www} \cdot d e f e n s o r d e l p u e b l o a n d a l u z . e s /$ sugerimos-una-norma-que-proteja-nuestro-patrimonio-naturalde-arboles-y-arboledas-singulares última revisión 28/02/2018. 
catálogo, "al tratarse de árboles cultivados, es la propia explotación agrícola la que determina cuándo deben ser renovados determinados ejemplares por la bajada de rendimientos, frecuente cuando el ejemplar alcanza una edad muy elevada. Debido a su condición de especie cultivada, tanto los ejemplares como el suelo en el que se desarrollan suelen ser de titularidad privada".

\section{CONCLUSIONES}

Podemos afirmar, con Fernández Salinas $(2008)^{34}$ que “en la actualidad, proteger una catedral en España, sea o no Patrimonio Mundial, es una terea relativamente fácil; por el contrario, señalar los valores de un silo de cereal de los años 50, la arquitectura sin arquitectos de los pueblos o la maquinaria de una antigua fábrica de sombreros resulta mucho más difícil”.

Tanto es así, que la preocupación de UNESCO por el tema del paisaje llevó a la elaboración de una propuesta de Recomendación para la Asamblea general de Unesco sobre una Convención Global del Paisaje, gestada en los años 2010 y 2011, pero que no ha llegado a cristalizar, a pesar de que recogía la necesidad -ya casi inaplazable- de contar con un nuevo instrumento normativo internacional sobre los paisajes ${ }^{35}$, reconociendo la entidad jurídica de este tipo de bienes. El Ministerio de Cultura y las administraciones autonómicas competentes, por tanto, deberían definir el marco legal de protección del paisaje con los instrumentos jurídicos que consideren necesarios. Permitiendo con ello la creación de distintos niveles de protección atendiendo a su reconocimiento administrativo o jurídico. "Deberían hacerse explícitas las consecuencias legales que recibe un paisaje al ser declarado jurídica y administrativamente como Paisaje de Interés Cultural. Algunas de estas consecuencias derivan de su condición de Bien de Interés Cultural, como por ejemplo: el paisaje será de «dominio público» (con la distinción de «dominio público»y «propiedad privada», pues, lógicamente, los particulares podrán ser propietarios parcial o totalmente de determinados elementos del paisaje, pero la Administración se encargará de proteger los

\footnotetext{
${ }^{34}$ Cit.pág. 30

${ }^{35}$ Ver referencia y mayor información en el ESTUDIO TEMÁTICO COMPARATIVO PARA EL PLAN NACIONAL DE PAISAJE: LOS PAISAJES DEL OLIVO EN ESPAÑA, trabajo de investigación realizado por CITEREA, equipo formado por Luengo Añón, A.; Moreno Herranz, F.J. ; Capdevila Galán, M., González García de Angela, J., Guzmán Alvarez, J.R. , Guzmán Casado, G. , Luengo Añón, M., Madero Montero,A., Troitiño Torralba, L., cit supra
} 
valores identificados en el paisaje); las modificaciones o alteraciones del Paisaje de Interés Cultural necesitarán de autorizaciones y será preceptivo -ya no sólo recomendable- la elaboración de un plan especial de protección de los mismos, etc. Se introducirán estos Paisajes de Interés Cultural en la legislación vigente sobre planificación territorial, así como en la de las políticas sectoriales (agrícola, forestal, economía, turismo, etc.). Así mismo, se pondrán en marcha programas de formación para especialistas, políticos, representantes de las administraciones, sobre el fomento de buenas prácticas paisajísticas"36

Hace falta, pues, y con urgencia, una normativa unificada (no un mero texto refundido) y sistemáticamente organizada, que recoja y regule los distintos aspectos que afecta a la protección de los paisajes culturales: desde su concepto, delimitación y caracterización, inventario y catalogación, así como el régimen jurídico de protección, sobre bienes de dominio público o de propiedad privada, dibujando el contenido de las servidumbres administrativas que por razón de protección del patrimonio cultural y etnológico deberían modalizar el contenido del derecho de propiedad y las indemnizaciones que las mismas podrían generar, los instrumentos de gestión, medios de comunicación con la administración competente en materia de protección del Patrimonio, así como el régimen sancionatorio, todo ello con carácter general, dejando el desarrollo reglamentario a las distintas Comunidades Autónomas.

Hace falta, pues, que desde los distintos foros jurídicos (tanto legislativos como investigadores) abordemos esta esencial tarea para la conservación de nuestra memoria natural, cultural y etnológica: es nuestro Patrimonio, y como tal, exige nuestro esfuerzo, luchando así contra la falta de reconocimiento institucional y social que sufre el paisaje, al no ser claramente identificado con un valor colectivo de interés cultural, en palabras del propio Plan Nacional de Paisajes Culturales, que identifica como riesgos de deterioro de dichos paisajes en nuestro país "la elevada vulnerabilidad del carácter del paisaje ya que dada su naturaleza territorial y visual, el paisaje está sometido a presiones de carácter urbanístico y especulaciones territoriales; los conflictos derivados de los derechos de propiedad, que pueden entrar en contradicción con los derechos de los ciudadanos de uso y disfrute del paisaje; las dificultades para su gestión apropiada, al ser un elemento patrimonial complejo, y sobre todo, la carencia de normativa legal al respecto.

\footnotetext{
${ }^{36}$ Luengo Añón, M. en "Valores patrimoniales" , "Estudio temático comparativo para el plan nacional de paisaje", cit.pags.87 y s,
} 